\title{
A Semiologia de Saussure como Epistemologia do Conhecimento
}

\section{The Semiology of Saussure as a Knowledge Epistemology}

Waldir Beividas

Universidade de São Paulo (USP), São Paulo, São Paulo, Brasil. waldirbeividas@usp.br

Resumo: Este texto apresenta argumentos para demonstrar a hipótese ampla de que o princípio de arbitrariedade do signo linguístico de Ferdinand de Saussure, tomado em sua radicalidade, e a proposição da Semiologia, disciplina a examinar em todas as suas consequências a presença e inserção do signo na vida humana, deixam entrever uma singular epistemologia discursiva. Os objetivos imediatos deste artigo procuram obter os primeiros resultados parciais: a demonstração da radicalidade do princípio saussuriano perante leituras que a minimizaram, senão tentaram neutralizá-la e a demonstração de que o ato semiológico dele derivado é mais que ato comunicativo de linguagem. É coerção inelutável da nossa apreensão e percepção do mundo. A metodologia seguida no raciocínio é inspirada nas reflexões epistemológicas do matemático R. Thom: a da estimulação da intuição na busca de novas simetrias implícitas escondidas nos fenômenos e ainda não conceptualizadas no campo geral da disciplina a que se submete. No presente caso, trata-se da busca da nova potencialidade epistemológica da ciência semiológica de Saussure.

Palavras-chave: semiologia; arbitrariedade; epistemologia; signo; conhecimento.

Abstract: The text presents first arguments to demonstrate the broad assumption that the principle of arbitrariness of the linguistic sign of Ferdinand de Saussure, taken in its radicalism, and the proposition of Semiology, discipline to examine the consequences of the presence and insertion of the sign in human life, they suggest a natural discursive epistemology. The immediate objectives of this article sought the first partial results: the demonstration of the 
radical nature of the Saussurean principle before readings that minimized, and tried to neutralize it, and the evidence that the semiology act thereof is a more communicative act of language. It is inescapable coercion of our apprehension and perception of the world. The methodology used in reasoning that is inspired by the epistemological reflections of the mathematician R. Thom: the stimulation of intuition in the search for new implied symmetry hidden in the phenomena and not yet conceptualized in the general field of the discipline undergoing. In this case, it is the new search for the epistemological power of Saussure's Semiology.

Keywords: Semiology; Arbitrariness; Epistemology; Sign, Knowledge.

Recebido em: 28 de dezembro de 2014. Aprovado em: 5 de maio de 2015.

Nunca nadie en la Historia del pensamiento hizo más con menos.

(Miguel Calvillo)

\section{Introdução}

Apresento aqui argumentos para defender a hipótese ampla de que o princípio de arbitrariedade do signo linguístico de Ferdinand de Saussure, se tomado em sua radicalidade maior, e a proposição da Semiologia, se disciplina a examinar em todas as suas decorrências o papel do signo na vida humana, deixam entrever uma robusta e singular epistemologia discursiva, de cunho imanente, como (única e básica) forma de conhecimento possível do homem sobre o mundo e sobre si: (i) epistemologia, porque, uma vez justificado esse estatuto, ela terá por força e função de disputar e rivalizar com a epistemologia vigente nas ciências naturais e a epistemologia regente das filosofias; (ii) imanente, porque, derivado do gesto arbitrário da acoplagem significante / significado, o ato semiológico cria o signo imanente e internaliza seu referente, oferecendo uma alternativa epistemológica de cognição ao 
realismo generalizado das ciências naturais e ao transcendentalismo congênito das filosofias; (iii) discursiva, enfim, porque o entendimento da ciência semiológica ultrapassa as estruturas linguísticas stricto sensu, abrange todas as linguagens na sua realização global, como discursos.

Perante essa hipótese ampla, os objetivos imediatos deste artigo visam obter como resultados, ainda que provisórios e parciais: (i) a demonstração da radicalidade do princípio do arbitrário perante leituras que o minimizaram, senão tentaram neutralizá-lo; (ii) a demonstração de que o ato semiológico dele derivado, mais que ato comunicativo de linguagem, é coerção inelutável da nossa apreensão e percepção do mundo.

A aposta de assim entender e demonstrar esse ponto de vista não foi trabalhada de modo concertado em nenhuma literatura linguística ou semiótica, embora para a investigação exploratória eu vá seguir várias e fecundas pistas ocorridas aqui e ali no pensamento de eminentes linguistas e semioticistas. Também ao que saiba, não encontrei em nenhum filósofo ou epistemólogo de metiê atenção mais detida nessa direção, conquanto algumas reflexões filosóficas de fenomenólogos contenham valiosas indicações, todavia aqui não inseridas, dados os limites editoriais impostos. De modo que a exploração da ideia de uma epistemologia discursiva a se construir derivada das proposições saussurianas sobre o princípio do arbitrário e sobre a Semiologia vai por conta e risco das escolhas e contingências de leitura que me aconteceram no curso da investigação, entre buscas planejadas e acasos deparados.

\section{Há cem anos com Saussure}

Considerada a perspectiva de mais de um centenário da morte de Ferdinand de Saussure e quase outro tanto da publicação do Curso de Linguística Geral (1995[1916]), é incontestável que seu pensamento tenha ganhado imensa difusão e notabilidade: notabilidade de fundação (estrutural) para inúmeros estudos e teorias contemporâneas na ampla área da linguística; notabilidade de indução (estruturante) em outros tantos estudos não linguísticos - da antropologia de Lévi-Strauss à psicanálise de Lacan. Se as ideias saussurianas não constituíram para 
todos eles alavancas mestras, tal como em Hjelmslev, Greimas, Benveniste, entre outros, estiveram difundidas como bússola de direção, como baliza de demarcação, ou mesmo como fronteira de franca contraposição. Nesse sentido, o presente texto visa explorar a fecundidade heurística que o pensamento de Saussure continua a exibir, como a testemunhar a epígrafe feliz e definitiva que empresto de $\mathrm{M}$. Calvilho: de fato, se pensamos que basicamente tudo proveio de um só livro, não escrito por ele, e sim de cursos compilados por alunos, e de poucos manuscritos, rascunhos não publicados por ele em vida, temos de convir mesmo: nunca ninguém fez tanto com tão pouco.

Não obstante tamanha notoriedade e difusão, um recanto singular do seu pensamento ficou aquém do que faz jus, do que acarreta e da atenção que deveria merecer. Refiro-me à proposição de sua Semiologia. Até as recentes descobertas de seus manuscritos, publicados nos Écrits (2002), as reflexões sobre a nova ciência, salvo engano não propositado, estiveram no mais das vezes apenas demarcando a geografia da sua ambição, a partir da geografia de duas páginas, se tanto, do Cours (2005): disciplina vasta que examinasse a vida dos signos na vida social, a Semiologia faria parte do campo da Psicologia Geral, campo que englobaria também a Linguística.

Sabemos bem, nenhuma Psicologia de porte a adotou, tendo sido acolhida apenas e basicamente pelo campo linguístico, como semiologia sígnica e comunicacional, que se desenhou nos anos 50 e 60 do primeiro século da linguística saussuriana - por R. Barthes, G. Mounin, P. Guiraud, E. Buyssens, L. Prieto, entre outros -, ou ainda pelo que veio a se transmutar, como teoria dos sistemas de significação: a Teoria Semiótica de L. Hjelmslev, A. J. Greimas, e seguidores próximos e menos próximos. Por economia do nosso trajeto aqui, não cabe estender comentários de como o primeiro grupo de autores conduziu suas teorizações semiológicas, nem como o segundo grupo transformou a semiologia saussuriana do signo em semiótica da significação.

E possível, no entanto, demonstrar que algo maior ficou escondido, não revelado, ou ao menos não estimado em toda extensão, algo que uma reflexão de R. Thom classificaria como uma simetria 
implícita ainda não explorada na proposição da Semiologia. ${ }^{1}$ Há a meu ver uma simetria filosófico-epistemológica na proposição da Semiologia saussuriana. Quero com isso indicar implicações de peso que decorrem do fato de o edifício semiológico se alicerçar no princípio do arbitrário do signo - arbitrariedade radical, expressão desaparecida da redação dada ao princípio no texto do Cours, tal como denunciado por Tullio de Mauro na sua edição crítica (2005, p. 442). Trata-se de evidenciar que a Semiologia de Saussure tem o propósito de estipular para todo tipo de linguagem - a ser progressivamente estendida a todo tipo de percepção, ação, sensação e cognição humanas -, a geração do sentido onde antes nada havia. Trata-se de demonstrar que a Semiologia se propõe de maneira tal que ultrapassa a discussão, localizada, da natureza apenas teórica e descritiva das línguas e linguagens, ou da distribuição de tarefas entre as ciências dos sistemas significantes. Noutros termos, o sentido, gerado pelo ato semiológico, ato de arbitrariedade radical, nos mergulha num verdadeiro problema de ordem filosófica e, mais diretamente, epistemológica. A questão do sentido, produzido semiologicamente, é questão de estatuto filosófico, questão ainda não enfrentada cara a cara, por assim dizer, pelo campo da linguística e da semiótica, bem como, arrisco-me a dizer, nem mesmo a contento pelo campo da filosofia.

Alguém poderá logo objetar desde a margem filosófica do rio: e Merleau-Ponty?, e Jacques Derrida, entre outros, notórios leitores de Saussure? Temos de convir: conceder que o linguista de Genebra tenha sido visitado pela pena de grandes filósofos como esses, entre os poucos que o fizeram, não significa se convencer de que tal visita tenha provocado alguma indução relevante em suas próprias filosofias, ou que tenha avançado integralmente na questão do sentido, na ótica semiológica. Correndo talvez o risco de grave injustiça, chamaria visita de cortesia a Saussure, por parte de poucos filósofos, visita que não produziu nenhuma nova inflexão em seus entendimentos sobre a

${ }^{1} \mathrm{O}$ grande matemático, criador da chamada Teoria das Catástrofes, propalava a busca de simetrias implícitas ou organização escondida a serem alvos da reflexão científica, quando esta privilegia a estimulação da intuição na tarefa de uma conceptualização forte sobre os fenômenos humanos, contra a ideia generalizada e massiva da experimentação laboratorial das ciências exatas que denuncia ser considerada por seus pares como melhor fonte de conhecimentos $(1985,1986)$. 
linguagem, nenhuma nova inflexão sobre o entendimento já milenar que a filosofia tem da linguagem, qual seja, a de mero instrumento e veículo do pensamento, da Razão, da Lógica; enfim, nenhuma contribuição mais decisiva sobre o papel peremptório da linguagem, seja na fundação do pensamento, seja na criação da única realidade disponível ao homem, tal como decorre da reflexão sobre o experimentum mentis de Saussure em tentar pensar o pensamento e o mundo, caso tudo fosse abstraído da linguagem:

[...] abstração feita de sua expressão por meio das palavras, nosso pensamento não passa de uma massa amorfa e indistinta [...]. Tomado em si, o pensamento é como uma nebulosa onde nada está necessariamente delimitado. Não existem ideias preestabelecidas, e nada é distinto antes do aparecimento da língua (SAUSSURE, 1995, p. 130 - eu destaco os dois nada).

Notemos desde aqui que o segundo nada é mais denso, hiperossemântico perante o primeiro. No que começa a nos concernir, podemos ler a citação acima da seguinte maneira: nada, absolutamente nada antes da língua, isto é: nada de pensamento, bem como nada de tudo o mais, antes da língua. ${ }^{2}$

Para dizê-lo de modo breve e cabal, entre filosofia e semiologia saussuriana há uma passarela ainda não transitada no quanto o deveria. Por isso é de se saudar no campo semiótico-linguístico o acontecimento, raro, de quando um filósofo como P. Maniglier toma como objetivo central de sua tese de doutoramento refletir filosoficamente sobre $A$ vida enigmática dos signos (2006). Ou seja, se pensamos comparativamente a outras ciências, a reflexão filosófica e epistemológica sobre as proposições saussurianas em Semiologia, sobre as concepções de linguagem dela derivadas e sobre a questão filosofal do sentido daí

\footnotetext{
${ }^{2}$ Com a ressalva de que a expressão antes da língua não insere qualquer endosso à ideia de busca das origens da linguagem no grito humano. $\mathrm{O}$ antes pode muito bem ser concebido como fora. Por sua vez, defender o primeiro nada e ampliá-lo para o segundo constitui o desafio inteiro da hipótese global aqui em construção.
} 
decorrente, é bastante recente, pontual e localizada, portanto ainda aquém do que deve e cabe.

$\mathrm{Na}$ margem linguística do rio, há e sempre houve grande reticência e resistência do linguista de profissão diante do vasto mundo intrincado do conceptuário filosófico. Intimidado pelo prestígio enorme e milenar de que goza a vizinha no mundo das idéias humanas, guardiã severa do pensamento, a sancionar as demais disciplinas para o melhor tanto quanto para o pior, o linguista prefere sentir-se mais confortável na cozinha das descrições, e fazê-las com sua competência, de hábito, do que na sala das cogitações, e claudicar em má filosofia, de diletante. E assim foi desde Saussure, a envolver até mesmo nomes eminentes como Hjelmslev, Benveniste e Greimas. Determinadas proposições desses notáveis linguistas costeiam a margem filosófica da questão semiológica do sentido, mas não aportam nelas seus barcos para uma exploração, digamos, mais funda.

Se quisermos desde aqui um rápido exemplo em Benveniste, basta reportarmo-nos à sua reflexão no artigo em que demonstra, longa e finamente, que as categorias do pensamento se subordinam às categorias de língua: "É o que se pode dizer que delimita e organiza o que se pode pensar. A língua fornece a configuração fundamental das propriedades reconhecidas nas coisas pelo espírito" (1991, p. 76).

Benveniste conclui o artigo com uma frase bem saussuriana: "pensar é manejar os símbolos da língua" (p. 80). Desnecessário frisar a ordem filosófica e epistemológica desse entendimento. Mais que isso, quando em reflexão pouco posterior dá uma "Vista d'olhos sobre o desenvolvimento da linguística" (1991, p. 19-33), nos anos 60 do século de sua vida, Benveniste chega a uma formulação ainda mais radical. Não é apenas o pensamento que se curva à linguagem, a própria realidade tem de o fazer: "A linguagem re-produz a realidade. Isso deve-se entender da maneira mais literal: a realidade é produzida novamente por intermédio da linguagem" (p. 26 - mantenho a separação silábica de ênfase e o itálico do original, o que não foi feito na tradução).

Mas logo em seguida o eminente linguista se demite perante o custo filosófico da formulação: 
Surgem aqui imediatamente graves problemas que deixaremos para os filósofos, principalmente o da adequação do espírito à "realidade". O linguista por seu lado estima que não poderia existir pensamento sem linguagem e que por conseguinte o conhecimento do mundo é determinado pela expressão que ele recebe [...] A "forma" do pensamento é configurada pela estrutura da língua (1991, p. 26).

Ora, por que razão, linguistas, estimamos não poder haver pensamento sem linguagem e logo abandonamos aos filósofos a equação espírito / realidade? A demissão se torna injustificável quando é de nosso quinhão levar às últimas consequências as implicações e configurações que a linguagem, por meio do ato semiológico, impõe ao pensamento e à realidade.

Então, o problema resta por inteiro, em círculo vicioso: o filósofo em geral põe em cena a finura de seu pensamento sobre uma filosofia do sentido, mas tem compreensão da linguagem que não lhe faz jus, em grande parte nomenclaturista, implícita ou sub-repticiamente, por vezes reduzida a mero veículo de expressão de um pensamento já bem armado de antemão, com antecedência e prioridade, pela Razão; linguagem por vezes reduzida a instrumento de captação ou representação de um mundo já bem organizado, em realidade completa, suficiente, independente. Mesmo respeitadas eventuais posições mais bem matizadas sobre isso, em todo caso, a filosofia, no geral, não conhece a linguagem de seu interior.

A questão se impõe: como terá de ser a reflexão epistemológica de uma disciplina, a Semiologia, que se mantenha convenientemente no âmbito de seu próprio ponto de vista interior, isto é, imanente à linguagem, mas que, ao mesmo tempo, adentre e interfira na ordem filosófica e epistemológica da questão do sentido? que possa dialogar com a Magna Philosofia e também com a epistemologia das ciências naturalistas, sobretudo neurociências e cognitivismos atrelados, no intento de enfrentar diretamente a equação espírito / realidade?

Perante o quadro assim desenhado, de um vazio incômodo entre as proposições semiológicas, em teoria e descrição, e as implicações filosóficas e epistemológicas que elas acarretam, minha maneira pessoal 
de retomar Saussure num retorno à Semiologia, nos limites deste texto, toma o rumo incômodo de procurar alguma pista e tentar entrar nesse vazio, entre ousadia e temeridade.

Introduzo então brevemente aqui em reflexão liminar - a qual pede pesquisa mais ampla que urge acontecer e programa coletivo que ultrapasse limites pessoais de reflexão - o objetivo de investigar o alcance epistemológico da proposição da Semiologia de Saussure, e defender para ela o estatuto de uma epistemologia discursiva perante o tribunal da grande filosofia e o tribunal das ciências naturalistas. Tratase, pois, de acionar um ponto de vista semiótico-linguístico sobre a ordem filosófica que o sentido gerado em semiologia adentra, e não de algum ponto de vista filosófico sobre o fato linguístico e semiótico do sentido.

\section{0 arbitrário e o ato semiológico}

Às vezes, porém, é mais fácil descobrir uma verdade do que lhe assinalar o lugar que lhe cabe.

(Saussure)

Curioso notar que a frase acima Saussure a tenha expressado justo num parágrafo em que introduz reflexões sobre o princípio do arbitrário do signo linguístico $(1995$, p. 82). Onde localizar essa verdade que acaba de ser descoberta ou ao menos estipulada a seu modo?

Salta aos olhos na proposição a centralidade e abrangência dele: o princípio "domina toda a linguística da língua; suas consequências são inúmeras" (p. 82). De imediato, isso indica que o linguista de Genebra quer erigir uma estaca de fundação, em linguística, para engendrar o objeto próprio, da linguística. A unidade básica da língua, isto é, o signo linguístico é arbitrário. É gerado por um ato - é como penso poder entender o "sentimento da língua" como o expressa Saussure (2002, p. 184). É o ato de junção interna, entre signans e signatum, junção arbitrária, tanto quanto será arbitrária a relação do todo gerado com o designatum apontado, o seu referente, a coisa significada. Convém entender $\mathrm{o}$ ato de junção dos dois planos do signo da maneira mais 
consequente e radical. Se seguimos uma definição de ato por Greimas, que a considera ingênua mas também a menos comprometedora, como "aquilo que faz ser" (2014, p. 80) - definição sintética, eficiente, suficiente - tal ato semiológico tem duas consequências de grande alcance teórico:

(i) essa junção, ou esse ato, faz nascer, FAZ-SER, o singular fato linguístico como fenômeno. $O$ fato linguístico não é um dado a priori, dado positivo, existente prévio, e sim o resultado, de uma relação atuada - relação de "oposição complicada", enuncia Saussure quando reflete em seus manuscritos sobre o princípio fundamental da semiologia (2002, p. 70); relação entre "elementos complexos" (p. 18); relação enfim que se desdobra e complexifica expansivamente criando os valores diferenciais implicados em todos os níveis pelos quais a língua vai articular seus signos - desde os níveis elementares das "substruções da linguagem" (p. 71) - o que hoje podemos seguramente afirmar: do fonema mínimo ao discurso máximo; ${ }^{3} \mathrm{e}$

(ii) essa junção, ou esse ato complicado entre signans e signatum, também faz nascer, FAZ-SER o ser do ser, isto é, toda a realidade do ser que se deixa ver como mundo para o falante. Aqui sobressai o alcance epistemológico e filosófico da estipulação do princípio da arbitrariedade e da operação semiológica.

Teremos a oportunidade de retomar logo adiante esse ato de junção e refletir mais detidamente sobre o papel do arbitrário. No momento, basta-nos entender que arbitrário não quer dizer aleatório, submetido a contingências curtas e imediatas do falante individual, ainda

\footnotetext{
${ }^{3}$ Importa dizer que as expressões complicada e complexa - em itálicos no original certamente não se referem a usos de acepções corriqueiras de hoje, de baixo semantismo, e sim fazem pesar suas etimologias lexicais e sufixais. Igualmente, substrução, termo pouquíssimo recuperado nos estudos linguísticos posteriores, tem o inestimável sentido de: raiz, base, fundamento, alicerce, fundação, enfim, construção feita por debaixo de outra (cf. Dicionário Houaiss).
} 
que saído de uma contingência histórica $a b$ initio, e sofrendo continuamente contingências da história no decurso. Nesse ato de junção sobressai uma lógica singular e estrita a fundar o signo. Essa lógica singular vai criar e gerenciar o signo na vida social do homem e toma o nome de uma vasta disciplina: a Semio-logia. Então, ter de reconhecer que o ato arbitrário a criar o signo com sua lógica estrita se deixa ver como um ato semio-lógico não me parece dedução incorreta. Pelo momento, basta-me apontar que a conexão do princípio do arbitrário do signo com o ato semiológico que ele desencadeia não parece ter tido muita repercussão enquanto tal, nem ter sido muito trabalhada por linguistas, salvo leitura insuficiente, a despeito da imensa repercussão geral do pensamento saussuriano.

Nesse encaminhamento, convém esclarecer primeiramente que tomo aqui o conceito do semiológico não no seu sentido mais clássico e difundido, extraído do Curso de Saussure, isto é, de seus votos de fundação de uma ciência que tratasse, de direito e de fato, mais amplamente do que a Linguística, o problema da presença viva dos signos no interior da vida social, para nos ensinar "em que consistem os signos, que leis os regem" (1995, p. 24). Quero entender aqui por semiológico algo mais simples, já presente desde os primórdios do pensamento saussuriano: o ato simples e elementar de junção dos dois planos do signo, ato de semiose. Porém, introduzo este adendo em hipótese: ato de junção deduzido e inteiramente hipotecado pelo princípio de arbitrariedade do signo (linguístico por preponderância, não por suficiência, linguageiro por abrangência). Ato semiológico equivale, pois, em suma, a todo ato de linguagem em geral, praticado como sentimento e consentimento de língua pelo falante.

Restam ainda dois últimos esclarecimentos: (i) ao retomar o termo semiológico, não quero com isso privilegiar a opção dos estudos semiológicos direta ou indiretamente derivados das proposições barthesianas, muito menos o de postular como necessária e prévia a mediação das línguas naturais no processo de construção e leitura do mundo e dos significados das semióticas não verbais; (ii) o propósito é preparar a reflexão para o que a espera nos seus desdobramentos futuros: estar o semio-lógico da operação de semiose, frente a frente com o fenômeno-lógico das operações perceptivas; estarem frente a frente a 
epistemologia saussuriana e a fenomenologia filosófica (Husserl e Merleau-Ponty) e, por fim, frente à frente à equipagem neuro-lógica das operações cerebrais de captação da realidade nos estudos cognitivistas e naturalistas das ciências. Os limites deste texto liminar impõe apenas começar a ressaltar o valor, portentoso tanto quanto peremptório, que o princípio da arbitrariedade e o ato semiológico dele derivado podem representar numa perspectiva epistemológica do conhecimento.

\section{Arbitrário vs. Necessário}

Quando o tema é este, não se pode evitar a leitura de Émile Benveniste em crítica severa ao princípio saussuriano do arbitrário, num breve texto intitulado "Natureza do signo linguístico" (1991, p. 53-59). À primeira vista, o texto quebra a espinha dorsal do princípio, ao procurar demonstrar o que o linguista crítico entende serem as incoerências de Saussure nas formulações e exemplos propostos, e ao procurar introduzir sua própria tese de que a relação entre significante e significado não é arbitrária, mas necessária. Toda reverência do mundo não impede, no entanto, que tenha fortes discordâncias perante a leitura do eminente linguista. Tenho-as em três pontos essenciais das suas críticas, vital que é para a presente reflexão a defesa da legitimidade teórica e epistemológica do princípio da arbitrariedade, rumo à hipótese de uma epistemologia discursiva derivada da Semiologia saussuriana.

Reproduzo sinteticamente o cerne de suas críticas às definições de Saussure sobre o princípio do arbitrário do signo. Benveniste elege para tal a definição em que Saussure entende a natureza do signo linguístico como arbitrária, porquanto seu significante é imotivado perante seu significado:

[Saussure] declara literalmente (p. 100), que "o signo linguístico une não uma coisa e um nome mas um conceito e uma imagem acústica". Garante, logo depois, que a natureza do signo é arbitrária porque [ele] não tem com o significado "nenhuma ligação natural na realidade". Está claro que o raciocínio é falseado pelo recurso inconsciente e sub-reptício a um 
terceiro termo, que não estava compreendido na definição inicial. Esse terceiro termo é a própria coisa, a realidade. Saussure cansou-se de dizer que a ideia de "sœur" não está ligada ao significante $s-\ddot{o}-r$, porém não pensa menos na realidade da noção. Quando fala da diferença entre $b-\ddot{o}-f$ e $o-k-s$, refere-se, contra a vontade, ao fato de que esses dois termos se aplicam à mesma realidade. Eis aí, pois, a coisa, a princípio expressamente excluída da definição do signo, e que nela se introduz por um desvio e aí instala para sempre a contradição (1991, p. 54 - explicito entre colchetes o $[e l e]$ acima, referente a il no original, para o argumento logo a seguir).

A leitura global de Benveniste sobre as formulações de Saussure enseja-lhe outros reproches, além das acusações acima de raciocínio falseado e permanente contradição, tais como "anomalia no raciocínio", ou como "afrouxamento da sua atenção" (p. 55).

Podemos notar, pelo longo extrato acima que são dois os lugares em que Benveniste nota o que entende serem as contradições de Saussure: (i) na definição do signo como arbitrário, logo fazendo entrar nele, a realidade, a coisa expressamente excluída de início da definição do signo; (ii) nos exemplos, primeiramente o exemplo sœur, em que Saussure diz não haver no seu significado nenhuma relação interna com a sequência sonora $s-\ddot{o}-r$, seu significante e, em seguida, o exemplo comparativo interlínguas bæuf e ochs. Um terceiro ponto essencial a incluirmos no exame é a recusa de Benveniste em aceitar como arbitrária a relação interna significante-significado e defendê-la como necessária, na sequência de suas críticas.

O primeiro ponto essencial em minha discordância da leitura de Benveniste incide simples, conquanto gravemente, no fato de que ele citou mal o texto de Saussure, ou antes, leu com imprecisão uma parte nuclear do texto saussuriano, o que lhe deu mote à crítica. Vejamos o texto de Saussure: "queremos dizer que o significante é imotivado, isto é, arbitrário em relação ao significado, com o qual [ele] não tem nenhum laço natural na realidade" (1995, p. 83 - o dêitico ele foi aqui introduzido entre colchetes para a sequência da argumentação). 
Ora, mesmo a despeito de alguma pequena diferença entre os tradutores do Curso e do texto de Benveniste, basta compararmos o texto de Saussure com o que dele cita Benveniste para verificar facilmente que o il dos dois textos são dêiticos anafóricos de dados completamente distintos. No texto de Saussure em questão, o il refere-se nitidamente a significante, jamais a signo. E Benveniste erroneamente o tomou por signo. Caso o linguista de Paris fosse mais fiel ao texto de Saussure, teria utilizado em seu texto elle, isto é, a imagem acústica, e não il (signo). $\mathrm{O}$ afrouxamento, dessa feita da sua própria atenção, acabou por levar o crítico a atribuir ao criticado o peso da invasão da coisa mesma ou da realidade, acusando-o de ter falseado o raciocínio por um recurso inconsciente e sub-reptício a um terceiro termo, como visto na citação longa acima. Mas esse recurso ou sub-repção não pode, a meu ver, ser atribuído no episódio diretamente a Saussure. Não é o signo que não tem com o significado (?!) nenhuma ligação na realidade. Aliás, o estranho da frase faz caber a pergunta: como poderia um signo, formado por significante e significado, não ter nenhuma ligação com o significado?! Como se vê, a leitura em falso de Benveniste o leva a emitir uma frase que carece de sentido, esta, sim, incoerente e contraditória, o que comprometeu seu entendimento perante o texto saussuriano no trecho examinado. Nesse comprometimento, comete Benveniste mais dois deslizes, além do nonsense acima: (i) haver especulado que Saussure pensa "contra sua vontade", ou ainda, que não teria deixado de pensar na "realidade da noção". No caso, a especulação não esteve em Saussure, mas na leitura desviada de Benveniste; (ii) por sua vez, a última expressão "realidade da noção" é, no mínimo, estranha, incabível no contexto da argumentação, novo nonsense, portanto.

Ora, está bem posto no texto de Genebra: o significante não tem nenhum laço natural na realidade com o significado. Quer isso tão somente dizer que não há nenhuma relação de conexão natural entre o significado (de sœur, ou bœuf) com a porção sonora do som $[s-\ddot{o}-r]$ ou $[b-\ddot{o}-f]$. Para tal significado, a língua poderia ter fixado em significante não importa qual outra sequência de sons, arbitrariamente, portanto. Aos olhos de hoje e de tudo o que se pôde progredir nas interpretações próSaussure, ele teria tido maior felicidade, ao que parece, se tivesse dado um ligeiro complemento à sua frase: o signo é arbitrário porque o 
significado não tem com o significante (imagem acústica) nenhuma ligação natural na realidade (material do som). Nenhuma propriedade natural do som é determinante na escolha do significado. Em suma, mesmo sem tal adendo é a este último entendimento que remete o texto literal de Saussure, não a leitura em falso por Benveniste.

Decorrente da primeira, a segunda discordância quanto às críticas de Benveniste incide numa outra imprecisão sobre o que colhe de Saussure. O crítico lembra: quando Saussure fala da diferença entre [b-ö$f]$ e $[o-k-s]$, ele se refere "contra a vontade" ao fato de que esses dois termos se aplicam à mesma realidade (cf. o longo trecho acima). Eis então a coisa entrando pelas portas do fundo. Mas a letra do texto de Saussure não diz isso. Não é a coisa-boi mas o significado-boi que tem por significante $[b-\ddot{o}-f]$ de um lado da fronteira e $[o-k-s]$ do outro (1991, p. 82). Então, Saussure não comete no episódio o deslize de fazer entrar brutalmente o referente, a coisa-boi, mas deixa-o fora, retendo apenas o significado-boi. Especular o que Saussure estaria pensando, sem o querer, não me parece, pois, suficiente para endossar a crítica de Benveniste.

A terceira discordância é quanto à sua argumentação para erradicar o arbitrário da relação significante-significado e introduzir aí a necessidade. Parece-me ter sido Benveniste vítima de uma falsa disputa entre conceitos que não se sobrepõem, menos ainda se excluem. Eis a argumentação do linguista crítico:

Entre o significante e o significado, o laço não é arbitrário; pelo contrário, é necessário. $\mathrm{O}$ conceito ("significado") "boi" é forçosamente idêntico na minha consciência ao conjunto fônico ("significante") boi. Como poderia ser diferente? Juntos os dois foram impressos no meu espírito; juntos evocam-se mutuamente em qualquer circunstância. Há entre os dois uma simbiose tão estreita que o conceito "boi" é como que a alma da imagem acústica boi (1991, p. $55-56)$.

M. Arrivé considera a demonstração indiscutível, mas frágil e neutra quanto à questão do arbitrário e da necessidade. Não faz mais, 
segundo ele, do que repetir a relação de pressuposição recíproca da metáfora da folha de papel de Saussure (2010, p. 67). No meu entender, a demonstração de Benveniste é antes insuficiente e, portanto, discutível. Se entendemos que o princípio do arbitrário introduz um pacto semiológico (sentimento da língua), isso quer dizer que há aqui dois tempos, ou duas coerções epistemológicas. O princípio do arbitrário significa que, na determinação de um significante para seu significado, tudo ficou e fica assim pactuado, tudo foi e é pacto semiológico tácito (e pacífico), sentimento de língua: "dizemos homem e cachorro porque antes de nós disseram homem e cachorro", diz Saussure com simplicidade igual à profundidade implicada $(1995$, p. 88$) .{ }^{4}$ As duas coerções assim se desdobram:

(i) arbitrário quer dizer: a determinação de um significante para um significado foi uma (qualquer); nada há ou houve de natural naquele que tenha induzido este, e vice-versa; poderia ter sido outra qualquer a pactuação, igualmente arbitrária e legítima: a relação não é causal, mas, por assim dizer, casual; e

(ii) mas uma vez assim determinada, um significante para seu significado, a relação se torna de pronto obrigatória, necessária. $\mathrm{O}$ falante não tem outra escolha senão absorver em sua aprendizagem e assumir em língua o pacto semiológico assim instaurado: dizemos homem e cachorro porque assim o disseram nossos pais.

Noutros termos, Saussure considera que dois fatores agem antinômicos, mas que atuam conjuntamente "no fenômeno total": "a convenção arbitrária em virtude da qual a escolha se faz livre, e o tempo, graças ao qual a escolha se acha fixada" $(1995$, p. 88 - itálicos meus). Portanto, arbitrário e necessário, mesmo antinômicos, não são

\footnotetext{
${ }^{4}$ A expressão pacto tácito é tentativa, se válida, de evitar a ideia de alguma consciência ajustada em convenção lúcida e premeditada. O sentido do aspecto convencional que deve prevalecer para a expressão é aquele ditado e consolidado pelo uso ou pela prática no fator tempo (descartada a questão da consciência desperta do falante ou aquela da origem da língua).
} 
excludentes: o primeiro é condição da instituição da língua; o segundo, condição de seu funcionamento e uso. Benveniste, ao que parece, reteve apenas o segundo e deixou escapar o primeiro. Portanto, nada há no aspecto necessário da relação significado-significante que mine ou elimine o estatuto arbitrário prévio da constituição do signo.

Por último, esta terceira discordância para com Benveniste desdobra-se numa quarta. Com efeito, se o acoplamento significante / significado é necessário, é porque há entre eles, segundo o linguista crítico, uma simbiose corpo / alma. Diante disso, o mesmo argumento valeria para a relação boi-signo / boi-coisa: se repetimos suas próprias palavras acima, em conjunto, eles se evocam em toda circunstância, para o falante. Portanto, a relação também aqui seria, por franca similaridade, necessária e não arbitrária. $\mathrm{O}$ fato de o mesmo boi-coisa ter como signo dois signos diferentes nos dois lados da fronteira não é questão do falante, do sentimento da língua, mas problema metalinguístico, ou interlinguístico, do linguista, ainda que o próprio falante possa ocupar esse lugar quando lhe ocorre porventura conhecer ambas as línguas. Benveniste teria então caído na mesma cilada que apontou em Saussure: a coisa continuou entrando pela porta dos fundos, desta feita na casa do crítico. $^{5}$

Para galgar passo a passo o fundo do (difícil) problema, portanto ainda em aberto, se alguma derrapagem há em Saussure, nos exemplos dados (bœuf, sœur), não está na introdução sub-reptícia da realidade, do referente boi-coisa, mas, sim, como bem aponta Arrivé (2010, p. 60-61), no fato de que Saussure resvala em erro denunciado por ele próprio logo na abertura do capítulo sobre a "Natureza do signo linguístico". É quando critica a concepção nomenclaturista que "supõe ideias completamente feitas preexistentes às palavras" (1991, p. 79). O exemplo dado por Saussure não escaparia desse nomenclaturismo: haver como ideia-boi um mesmo significado preexistente aos significantes dos

${ }^{5}$ Se me permito ser incisivo nessas discordâncias, é em nome de certo equilíbrio que precisa ser reparado. Os descuidos de atenção de Benveniste custaram caro e ainda custam muito para a defesa do princípio. Deu margem e munição farta para vários linguistas, entre eles o grande R. Jakobson, teóricos contrários ao princípio da arbitrariedade, em boa medida, no meu entendimento, por conta de Benveniste e sua (merecida) autoridade no campo. 
dois lados da fronteira. Arrivé nota essa desatenção de Saussure que trai suas próprias reflexões bem postadas. É o que se comprova em outra passagem, desta feita nos manuscritos editados por R. Engler: "Se as ideias estivessem predeterminadas na mente humana antes de serem valores linguísticos, uma das coisas que forçosamente ocorreriam é que os termos de uma língua corresponderiam exatamente aos de outra" (apud ARRIVÉ, 2010, p. 61).

Não obstante a inflexão um tanto forçada que Benveniste destila em Saussure em sua citação também desatenta, é bem útil começar a discutir mais densamente sobre a entrada furtiva do referente, passível de rondar os exemplos saussurianos, e rondar quaisquer outros exemplos que venhamos porventura utilizar. Essa questão é vital para os desenvolvimentos ulteriores das reflexões aqui em andamento, uma vez que Saussure, ele próprio, ao criticar a concepção ingênua da língua, como nomenclatura, evoca a coisa: "uma lista de termos que correspondem a outras tantas coisas" (1991, p. 79).

A suposta entrada sub-reptícia do referente na introdução do princípio do arbitrário é também o grosso das críticas de um outro linguista, no caso também psicólogo. É bem provável que Benveniste não tivesse tido conhecimento de outro texto crítico, publicado dois anos antes do seu, em 1937, por Edouard Pichon: "La linguistique en France : problèmes et méthodes", publicado em Journal de psychologie normale et pathologique" (cf. ARRIVÉ, 2010, p. 62). São vizinhos de crítica, cada um ao seu estilo, graves e veementes em Benveniste, lúcidas e virulentas, como o avalia M. Arrivé, em Pichon. Este parafraseia formulações de Saussure tais como as vistas acima:

[...] O signo é arbitrário, visto que um significante como [b-oè-f] [sic] não tem relação alguma com seu significado. A possibilidade para traduzir para o alemão o mesmo significado pelo significante [ò-k-s] é justamente a prova desse caráter arbitrário $(C L G$, 102).

Não é preciso ir muito além disso; o erro de Saussure é, a meu ver, flagrante e consiste no fato de ele não se dar conta de que introduz no decorrer da demonstração elementos que não estavam no 
enunciado. De início, ele define o significado como sendo a ideia geral de bæuf; em seguida, ele se comporta como se esse significado fosse o objeto chamado bæuf ou, pelo menos, a imagem sensorial de um bœuf [...] Ora, aí estão duas coisas absolutamente diferentes [...] Se é bem verdade que existem bois tanto na Alemanha quanto na França, não é verdade que a ideia expressa por [o-k-s] seja idêntica àquela expressa por [b-oè-f]. (Apud ARRIVÉ, 2010, p. 62$63)$.

Diferentemente de Arrivé, não entendo como lúcidas as observações de Pichon. Nota-se claramente que não aponta diretamente na citação algum equívoco explícito, apenas se contenta em indicar que Saussure, notemos bem, teria se comportado, no exemplo, como se... É uma afirmação no mínimo frágil e temerária, mais atribuível ao modo da leitura de Pichon do que a bem dizer evidente no exemplo concreto de Saussure. Voltarei a isso logo abaixo.

Ocorre, então, que tanto Benveniste quanto Pichon acusam Saussure com argumentos especulados, o primeiro levando-o a ter pensado "contra a vontade" na coisa-boi, o segundo imaginando um Saussure ter-se comportado como se o objeto sensorial (boi) estivesse presente. Coladas uma a outra, tais críticas, no meu entendimento, foram no geral mal fundadas, são, no mínimo, passíveis de suspeição, observada a letra do texto saussuriano. E o feitiço, por assim dizer, acaba virando contra o feiticeiro. Benveniste tanto quanto Pichon não deixam de se apresentar, em suas críticas, como vítimas (sem o querer?) do nomenclaturismo denunciado por Saussure na abertura do capítulo do Curso, sob crítica. Para evidenciar isso, basta que tenhamos em mente a posição que julgo a mais fecunda, a leitura de R. Amacker, que assim adverte: "Não há, quanto ao arbitrário linguístico, posição mediana: ou se considera a língua como radicalmente arbitrária [...] ou se é, de modo mais ou menos explícito, mais ou menos direto, um nomenclaturista" (1975, p. 88).

Com efeito, em Benveniste, esse nomenclaturismo mais ou menos inconfessado adquire contornos de um realismo, recôndito, que não coaduna com o radicalismo saussuriano do arbitrário: a coisa mesma, 
a realidade como substância exterior ao signo, tida como um terceiro, é colocada como algo pacífico, um existente fora do signo, a parametrar a relação entre signo-coisa, a qual Benveniste admite de bom grado como arbitrária. Mas a coisa permanece externa à linguagem. No entanto, segundo a radicalidade do princípio do arbitrário, não adianta se esconder atrás de signos - coisa mesma, realidade, substância, animalboi na sua particularidade concreta e substancial e mil outros signos congêneres - para enunciar algo terceiro, fora do signo. Todos esses recursos tentam contornar o problema, mas são esforços desesperados e sem eficácia, pois todas as expressões acima são igualmente signos, tão signos quanto o são bœuf e ochs, tão arbitrários quanto estes. Como querer ver na coisa mesma ou na realidade um tertius que não carregue o ônus, por assim dizer, ou, melhor dito, a façanha de ser igualmente signo e igualmente submetido à lei geral da arbitrariedade?!

Por sua vez, em Pichon, o nomenclaturismo se agrava até mesmo num realismo positivista ingênuo: "se é bem verdade que existem bois tanto na Alemanha quanto na França..." (cf. a citação acima - itálicos meus). A frase claudica em si própria: não há bois na Alemanha, isto é, na língua alemã! As fronteiras linguísticas do exemplo de Saussure foram trocadas realista e ingenuamente por fronteiras geográficas na pena de Pichon, e o boi-no-pasto ficou acatado como um existente autônomo, fora da língua, como ponto terminal da relação! Amacker continua tendo razão. Ora, é impossível tocar o dedo, por assim dizer, na carne-boi, pois tudo o que dissermos será dito com signos, jamais fora deles. Sob o imperativo do arbitrário do signo, o referente estará internalizado, para sempre. Resta o desafio de entender o que resta e qual estatuto resta ao que resta.

Tentemos salvar Saussure desse duplo ataque no seu texto e nos seus exemplos, segui-lo por novas vias e, com isso, continuar a defender a radicalidade do princípio do arbitrário. É certo que não vale tanto para isso o argumento clássico, embora justo, que quase todos os teóricos evocam em socorro: os exemplos são sempre ruins, atrapalham mais do que ajudam. Notemos primeiramente o seguinte: como se vê acima em Pichon, e mais claramente em todo o texto de Benveniste, acaba-se deslocando a questão do arbitrário para a relação do signo in totum perante o referente, a coisa, a realidade como um tertius. 
Para o que concerne globalmente a uma reflexão que tente radicalizar e robustecer o arbitrário, seria cômodo notar que Benveniste não denega a estipulação do princípio do arbitrário na relação signocoisa. Admite e concorda que tal relação é efetivamente arbitrária, embora, veremos logo mais, vá atenuar em seguida o seu alcance. Ora, será suficiente bastarmo-nos do argumento de autoridade numa questão que, no meu entendimento, é a mais difícil de demonstrar no horizonte de uma epistemologia de cunho semiológico? A facilidade sendo suspeita em matéria de epistemologia, convém trilharmos mais demoradamente o caminho, conquanto servindo-nos de boa pista oferecida pelo próprio Benveniste.

Embora admita a arbitrariedade na relação signo-realidade, Benveniste procura limitar sua zona de aplicação; atenua-a ao grau de contingência:

Vemos agora, e podemos delimitar, a zona do "arbitrário". O que é arbitrário é que um signo, mas não outro, se aplica a determinado elemento da realidade, mas não a outro. Nesse sentido, e somente nesse sentido, é permitido falar de contingência, e ainda assim é menos para dar solução ao problema que para assinalá-lo e afastá-lo provisoriamente (1991, p. 56).

Como se vê, Benveniste não apenas asseptiza o conceito radical de Saussure, anestesiando-o em baixa contingência, como desqualifica até mesmo esta, como se fora apenas espécie de saída honrosa para em seguida se demitir da tarefa, da solução. A demissão fica mais clara na sequência da reflexão:

De fato, esse problema não é senão o famoso $\varphi v ́ \sigma \varepsilon l$ ou $\theta \varepsilon ́ \sigma \varepsilon l$ e não pode ser resolvido a não ser por decreto. É, realmente, transposto em termos linguísticos, o problema metafísico da relação entre o espírito e o mundo, problema que o linguista estará, talvez, um dia, em condições de abordar com sucesso, mas que no momento fará melhor se o deixar de lado. Propor a 
relação como arbitrária é para o linguista uma forma de defender-se contra essa questão e também contra a solução que o falante lhe dá instintivamente (1991, p. 56-57).

Ora, até quando o campo linguístico terá de deixar esse problema para um futuro e se demitir perante suas dificuldades presentes? Estaríamos ainda, transcorridos setenta anos dessas formulações, com tudo o que de filosofia e de ciências cognitivistas e bioneurológicas se fizeram sobre a relação espírito / mundo, no intercurso, sem nenhuma chance de tentar arriscar alguma solução? Felizmente o próprio Benveniste ofereceu desde então a chave de uma primeira porta: "Para o falante há, entre a língua e a realidade, adequação completa: o signo encobre (recouvre) e comanda a realidade: ele é essa realidade (nomen, omen, tabus de palavra, poder mágico do verbo, etc.)" (1991, p. 57).

Os espaços deste artigo não permitem esgotar hipóteses e discutilas exaustivamente para uma tentativa de solução. Apenas quero notar aqui que Benveniste rebaixa a "adequação completa" signo-mundo a uma espécie de ingenuidade do falante comum, espécie de primitivismo cognitivo, a uma solução instintiva que só valeria para o homem comum, usuário ingênuo da linguagem. E o desafio (a enfrentar) que subjaz à hipótese de uma epistemologia discursiva é justo este: o que vale para esse falante ingênuo vale também para qualquer pensador penetrante, $o$ das profundas filosofias, bem como para qualquer cientista engenhoso, $o$ das eficazes ciências naturalistas.

\section{Pequeno entreato do princípio da arbitrariedade}

Detenho-me nesta pausa a apontar o que considero uma limitação ou insuficiência das discussões em torno do princípio da arbitrariedade. Salvo melhor juízo, elas se deram mormente na avaliação sobre o alcance metodológico dele. Para dizê-lo brevemente: na linguística, a maneira mais adequada de descrever a natureza do elemento de base da língua, o signo, é entendê-lo como dualidade íntima e inseparável (significante / significado), cuja relação é arbitrária, e em dois âmbitos. 
No âmbito interno à célula do signo, há uma relação de arbitrariedade de estatuto intrassígnico: (i) nada há ou houve na matéria fônica de um significante, na consubstancialidade natural de um som nem mesmo no que ela adquiriu como pertinência formal de fonema ou de morfemas lexicais e gramaticais-, que induza ou tenha induzido à imposição de seu(s) significado(s) pela história de outrora ou pela massa falante da língua de agora; (ii) igualmente nada há de natural no significado, não há eventual protótipo intrínseco do significado, que tenha induzido ou induza à determinação daquela cadeia fônica, fonema ou morfema específico para a efetuação da semiose sígnica. Tudo ficou e fica, assim, pactuado, tudo se tornou um pacto semiológico tácito, como sentimento de língua.

No âmbito externo à célula-signo, âmbito extrassígnico - sem fechar questão por enquanto sobre como entender algo fora-signo-, haverá arbitrariedade na designação-alvo do signo. O signo completo, composto arbitrariamente no seu interior, tem relação arbitrária também com seu designatum, seja este um dado substancial do mundo externo, uma imagem sensorial - os exemplos bøuf, sœur-, seja, ao contrário, um dado interno à própria cadeia discursiva, por exemplo, todas as formas igualmente arbitrárias pelas quais a língua compõe suas unidades morfológicas (lexicais e gramaticais, preposições, conjunções, conectivos...), suas estruturas narrativas e discursivas, qual seja, a gramática extensa, paradigmática e sintagmática, de todo discurso. Noutros termos, o princípio recobre todo o discurso em qualquer linguagem na acoplagem semiótica dos dois planos.

Assim, todo ato semiológico, arbitrário em seu fundamento e origem, se torna não livre, obrigatório e necessário; o falante não terá mais a veleidade da liberdade, ou a liberdade da veleidade, seja no âmbito intrassígnico, seja na remissão extrassígnica, ainda que o pacto tácito seja frágil por estar lançado na história material da língua, sujeita à ação do tempo na sua diacronia. O sujeito estará sempre, por assim dizer, condenado ao sentido desse pacto semiológico, tido por Saussure como "produto histórico", condenado a se curvar ao "mais recente compromisso que aceita o espírito com certos símbolos" (2002, p. 209). 


\section{A Semiologia: uma epistemologia do conhecimento}

Desvencilhemo-nos dos pesos semânticos graves que o termo epistemologia carrega em filosofia do conhecimento. Tomemo-lo simplesmente no sentido das decorrências possíveis que acarreta a estipulação saussuriana da arbitrariedade radical do signo, na base da sua Semiologia, isto é, das consequências que incidem não apenas sobre o modo como nos comunicamos sobre o mundo com linguagens, mas antes sobre o modo como concebemos o mundo pela linguagem, como o percebemos, como construímos todo o possível conhecimento sobre ele, via linguagens. Qual seja, estamos perante as implicações para as teorias do conhecimento sobre um mundo que se quer real e objetivo (das ciências exatas), e um mundo que se quer subjetivo, do espírito (das ciências humanas), perante $\mathrm{o}$ fato da presença determinante da linguagem no homem e da sua operação semiológica.

Nesse horizonte, temos de reconhecer que os dois parágrafos do Curso que dão direito de cidadania à nova ciência da Semiologia são pouco incisivos perante o que considero sua, por assim dizer, Certidão de Nascimento, apresentada em antigos manuscritos. Saussure batiza sua semiologia como "o estudo do que se produz assim que o homem tenta significar seu pensamento por meio de uma convenção necessária (2002, p. 262, itálicos meus).

Detenhamos um momento na pira batismal. A simplicidade surpreendente dos termos esconde uma exorbitância epistemológica. Eles nos levam a perguntar se essa frase não constrói de pronto uma epistemologia semiológica já inteira:

(i) o que se produz : em minha leitura produz-se aí o próprio mundo dos objetos disponíveis ao homem, construídos signicamente, o mundo mesmo das coisas e do humano, o único mundo possível, assim criado e estabelecido pela convenção necessária do universo dos signos. Elaborados em discursos, em variadas racionalidades discursivas, paulatinamente nascidas e crescidas na diacronia da História, tais signos vão gerenciar, em decorrência, todos os universos de discurso, científicos numa ponta, filosóficos na outra, poéticos numa terceira, e os demais discursos humanos nos 
entremeios. É pela fabricação semiológica dos signos, sobretudo por aqueles que criam enunciados acirradamente existenciais: as coisas são, a realidade existe, o mundo existe, existe a matéria do mundo, há montanhas, mares e florestas; é por tais tipos de signos existenciais que o mundo tomará a forma de uma ontologia espontânea, imediata, ao alcance das mãos e do olhar do homem, ao alcance do sentimento da língua do falante comum, seja como mundo real, objetivo, seja como mundo psíquico, subjetivo. Noutros termos, o mundo passa a se apresentar como espontaneamente real pela complicada maquinaria fonológica, morfológica, sintáxica e semântica-, dos signos em discurso, como produto do ato de signi-ficar o pensamento;

(ii) significar o pensamento: trata-se aqui do que vem a dar estatuto mesmo de pensamento propriamente dito à massa amorfa em nebulosa, das duas metáforas saussurianas (cf. atrás). Vejo aqui o imperativo epistemológico de exigir da filosofia ceder o passo e atribuir a primazia da linguagem perante o pensamento. $\mathrm{O}$ contrário disso é desconhecer a linguagem de seu interior, é desconhecer-lhe o papel na fundação do pensamento, desconhecer a integral peremptoriedade do ato semiológico de linguagem; e

(iii) convenção necessária: eis o alicerce arbitrário de todo o edifício epistemológico da semiologia saussuriana. Deixemos de lado o lado técnico, descritivo, do princípio da arbitrariedade. Não se trata, neste nível da reflexão, de distribuir os signos por graus de arbitrariedade ou de motivação, sincronicamente no sistema ou diacronicamente na história da língua. Importa na radicalidade do princípio que tudo, na composição do ato semiológico arbitrário do signo, poderia ter sido diferente, seja internamente entre os dois planos do signo, seja externamente na designação de seu alvo referente. É o que resume a tão aguda quão simples observação do filósofo P. Maniglier: "O signo utilizado não 
tem nenhuma razão positiva para ser este e não outro, mas, precisamente por isso mesmo, nenhuma razão também de ser outro (2006, p. 355). De maneira que o modo como tudo o foi é plenamente legítimo, ficou como ficou e ponto final (sem prejuízo dos fatores históricos que podem tudo alterar).

Por sua vez, tal arbitrariedade radical nos dispensa, com vantagem, de procurar o primeiro grito das origens da linguagem ou alguma motivação primeva saída do barro adâmico. Quanto a isso Benveniste teve novamente a boa formulação. Recusando a ideia simplista do entendimento da linguagem como instrumento fabricado pelo homem, o eminente linguista é assertivo:

A linguagem está na natureza do homem, que não a fabricou. Inclinamo-nos sempre para a imaginação ingênua de um período original, em que um homem completo descobriria um semelhante igualmente completo e, entre eles, pouco a pouco, se elaboraria a linguagem. Isso é pura ficção. Não atingimos nunca o homem separado da linguagem e não o vemos nunca inventando-a (1991, p. 285).

Mas o próprio Saussure já anunciava esse entendimento e, de certa maneira, prenunciava o que estou chamando de epistemologia discursiva a gerenciar o entendimento do mundo. Com efeito, sobre a questão da origem da língua ele é ferino e incisivo:

Nada prova melhor a nulidade de toda a pesquisa sobre a origem da língua [...].

Olhar a língua e se perguntar em que momento preciso uma tal coisa "começou" é tão inteligente quanto olhar o riacho da montanha e de acreditar que remontando-o encontraremos o lugar preciso onde ele tem sua fonte. Inumeráveis coisas estabelecerão (Des choses sans nombre établiront) que a todo momento o RIACHO existe enquanto se diz que ele nasce, e que reciprocamente ele só nasce enquanto se [ ] (2002, p. 93-94). 
Os enigmáticos brancos [ ] dos manuscritos impedem uma dedução mais abalizada do seu pensamento no episódio. O que importa nas últimas reflexões e questionamento das críticas de Benveniste e de Pichon é que o radicalismo do princípio do arbitrário do signo implica diretamente o descarte definitivo do referente externo. Isso fica patente quando Saussure reflete sobre a Semiologia nos antigos documentos manuscritos. Ao criticar a concepção adâmica e nomenclaturista dos filósofos da linguagem, Saussure refuta as concepções que partem de objetos a priori, dados de antemão:

Primeiro o objeto, em seguida o signo; portanto (o que negaremos sempre) base exterior dada ao signo e figuração da linguagem pela relação a seguir:

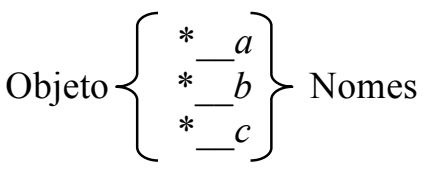

Enquanto que a verdadeira figuração é: $\mathrm{a}-\mathrm{b}-\mathrm{c}$, fora de todo conhecimento de uma relação efetiva como * a, fundada num objeto. Se um objeto pudesse, onde quer que fosse, ser o termo sobre o qual está fixado o signo, a linguística cessaria instantaneamente de ser o que é, desde o cume até a base; de resto o espírito humano de igual modo, como fica evidente a partir dessa discussão (2002, p. 230).

Não é difícil de se convencer do valor epistemológico dessas reflexões. Fora de todo conhecimento de uma relação efetiva como objeto / signo, fundada no objeto (exterior), é formulação suficiente para nos levar a deduzir que o referente designado pelo signo é um referente internalizado à linguagem e acenar um estatuto imanente à sua Linguística e portanto à sua Semiologia. Fora da radicalidade do princípio do arbitrário, do ato semiológico imanente, não só a linguística e demais linguagens cessariam de ser o que são, mas também cessaria de sê-lo o próprio espírito humano. É assim que vejo sua Semiologia anunciar uma verdadeira epistemologia (discursiva) do conhecimento. 


\section{A língua como Instituição pura}

Mesmo tomada com a brevidade aqui posta, a vasta e perene discussão em torno do arbitrário quase sempre tem deixado de lado o fato de que tal princípio não vem fortuitamente sem um agente. Trata-se do aspecto, menos discutido, de que ele induz e se deduz de um pacto, instituído como produto histórico em língua, como sentimento de língua pelos sujeitos falantes. E pacto tem justamente, ao mesmo tempo, o encargo de manter e comandar todo o ato semiológico, de linguagem, do sujeito falante.

Retenhamos primeiramente desse ato de linguagem, que estamos vendo como repactuação continuada e recorrente de um ato semiológico de fundação e de uso contínuo do signo, o fato de que ele advém de um pacto ou princípio de arbitrariedade:

$\mathrm{O}$ ato pelo qual $[\ldots]$ um contrato teria sido estabelecido entre os conceitos e as imagens acústicas - esse ato podemos imaginá-lo, mas jamais foi ele comprovado. A ideia de que as coisas poderiam ter ocorrido assim nos é sugerida por nosso sentimento bastante vivo do arbitrário do signo (SAUSSURE, 1995, p. 85-86).

Por sua vez, outro dado quase sempre no limbo secundarizado das reflexões sobre o arbitrário é que a língua tem, segundo Saussure, a natureza de Instituição humana, expressão creditada a Whitney, nas notas que esboçou para um artigo dedicado ao linguista: "Whitney disse: a linguagem é uma Instituição humana. Isso mudou o eixo da linguística" (2002, p. 211).

Não interessa propriamente aqui o contexto dessas proposições, não obstante importantes e epistemologicamente decisivas, que é o de acentuar seu estatuto de puro produto histórico e de combater a ideia da linguagem como faculdade natural, orgânica. $O$ que nos interessa de perto é o cerne dessas notas preparadas, em que Saussure compara a linguagem com outras instituições humanas, como o direito, o sistema político de uma nação, ou mesmo a moda. A reflexão está voltada para 
estabelecer uma profunda diferença de estatuto dessas instituições: elas são todas fundadas "(em graus diversos) sobre relações NATURAIS das coisas". A moda por exemplo "não pode se afastar um instante sequer do dado das [proporções] do corpo humano". E prossegue: "Mas a linguagem e a escritura NÃO SÃO BASEADAS numa relação natural das coisas". A linguagem, como bem sublinhara sem cessar Whitney, diz Saussure, é uma instituição pura, ao que reforça com veemência: isso "demonstra muito mais, a saber que a linguagem é uma instituição SEM ANÁLOGO" (2002, p. 211 - caixas altas no original).

Ressaltemos primeiramente o estatuto de Ins-ti-tu-i-ção, como se pela silabação conseguíssemos a façanha de aferir cada grama do peso (epistemológico) que esse ato implica. É relevante acentuar que trata-se de uma operação instituidora, constituidora, determinante do modo como o sujeito falante terá não apenas de designar as coisas do mundo externo e do mundo interno à linguagem, mas também instituidora do modo como ele estará liminarmente condenado, por assim dizer, a captar tudo no mundo dessa maneira e não de outra, ou seja, via ato semiológico arbitrário de soldagem, em semiose, do significado e do significante.

Noutros termos, entendido como instituidor da operação da apreensão do mundo, o ato semiológico impõe ao sujeito falante o modo como vai perceber e cogitar esse mundo. $\mathrm{O}$ ato semiológico impõe à percepção uma metamorfose colossal: uma apreensão registrada e cifrada quantitativamente pelos órgãos sensoriais, advinda do mundo bruto, cifras de frequência sonora, de raios luminosos, átomos odorantes, e demais puras quantidades que assaltam constantemente os sentidos, se transforma, por determinação semiológica, em uma significação resultada qualitativamente para o mundo da fenomenologia humana, o mundo da morfologia fenomenológica do homem. Pleiteia-se com isso uma primazia das morfologias linguageiras por sobre as morfogêneses orgânicas dos sentidos. É assim que o sujeito perceberá, no sentido pleno do ato, por exemplo, cores e arco-íris, bem entendido, cores que o pacto semiológico de sua língua oferece. É assim que dois sujeitos, com línguas diferentes perceberão diferentes cores em arco-íris, não obstante tenham igual sistema neuroperceptivo. É assim que um maestro perito, com ouvido adestrado pelas morfologias da semiologia musical, ouvirá uma única nota dissonante numa orquestra de dezenas de instrumentos, 
coisa que o ouvinte comum deixará passar despercebido, mesmo tendo equivalente aparelho de audição. E o mesmo vale para a região dos demais sentidos humanos. O vasto mundo da(s) Semiologia(s) cria o mundo da fenomenologia do homem à sua imagem e estrutura.

Estamos, pois, adentrando aqui o cerne da vocação epistemológica da Semiologia saussuriana, caucionada pelo ato arbitrário radical como princípio fundante. Aos linguistas, a tarefa de robustecer tal princípio e debatê-lo com as demais epistemologias do conhecimento.

\section{Referências}

AMACKER, R. Linguistique saussurienne. Genève: Dros, 1975.

ARRIVÉ, M. Em Busca de Ferdinand de Saussure. M. Marcionilo. São Paulo: Parábola Editorial, 2010.

BENVENISTE, E. Problemas de Linguística Geral I. Trad. M. G. Novak e M. L. Neri. Campinas: Pontes, 1991.

GREIMAS, A. J. Sobre o Sentido II. Ensaios Semióticos. Trad. D. F. da Cruz. São Paulo: EDUSP, 2014.

MANIGLIER, P. La vie énigmatique des signes. Saussure et la naissance du structuralisme. Paris: Éditions Léo Scheer, 2006.

SAUSSURE, F. Curso de Linguística Geral. 20 a ed. Trad. A. Chelini, J. P. Paes, I. Blikstein. São Paulo: Cultrix, 1995.

SAUSSURE, F. Écrits de linguistique générale. Paris: Gallimard, 2002.

SAUSSURE, F. Cours de linguistique générale. Edition critique par Tullio di Mauro, Paris: Payot, 2005.

THOM, R. La science malgré tout... Encyclopcedia Universalis (Symposium) Paris: Enciclopædia Universalis, France SA, 1985.

THOM, R. La méthode expérimentale: un mythe des épistémologues (et des savants)? In: HAMBURGER, J. (Dir.). La philosophie des sciences aujourd'hui. Paris: Gauthier-Villars, 1986. 